\title{
Sexual Function and Satisfaction Interfering Factors Subordinate Domain
}

National Cancer Institute

\section{Source}

National Cancer Institute. Sexual Function and Satisfaction Interfering Factors

Subordinate Domain. NCI Thesaurus. Code C131157.

A subgroup of PROMIS Sexual Function and Satisfaction item scales that assess selfreported perceptions of the degree to which various factors affect satisfaction with sex life in men and women. 